\title{
PREDICTORS OF WORK-RELATED WELL-BEING IN SECTOR EDUCATION TRAINING AUTHORITIES
}

S Rothmann and J Pieterse

WorkWell: Research Unit for People, Policy and Performance, North-West University, South Africa

\begin{abstract}
The objective of this study was to investigate the relationship between job demands, job resources, sense of coherence and work-related well-being of employees at Sector Education Training Authorities (SETA). The sample consisted of 159 SETA employees in South Africa. The Maslach Burnout Inventory - General Survey, the Utrecht Work Engagement Scale, the Orientation to Life Questionnaire, and the Job Demands-Resources Scale. The results showed that overload predicted exhaustion. Cynicism was predicted by limited growth opportunities, a lack of organisational support, and a weak sense of coherence. Vigour and dedication were predicted by growth opportunities, organisational support and a strong sense of coherence.
\end{abstract}

JEL J28, 81

\section{1 \\ Introduction}

The South African National Skills Development Strategy (NSDS) was developed from the need to address the imbalances between skills required for the development of a successful economy that promotes job growth and skills currently available in South Africa. The overwhelming number of black people in particular who are illiterate and unskilled is a result of the former apartheid and job reservation policies in South Africa. The Department of Labour initiated the broadening of access to adult basic education and training in an effort to address the shortage in adult basic skills and education. By placing unemployed and employed young people into learnerships, the government aims to equip South Africans with the necessary skills and relevant experience to find permanent employment. These steps were identified as key objectives in achieving equity and empowering those groups previously marginalised by the apartheid policies.

The National Skills Development Strategy, a product of the Skills Development Act, gave rise to the Sector Education Training Authorities
(SETAs). SETAs are the implementing agencies of the skills development strategy. While there were specific successes, the SETAs have not been an overwhelming success. The National Skills Development Strategy (NSDS), underpinned by the Skills Development Act 1998, has entered its second five-year cycle (2005-2010). The NSDS has left in its wake some casualties such as the reduction in SETA numbers from the initial 25 to 22. Problems identified within the SETAs can be summarised under three headings, namely lack of proper governance, poor management and ineffective strategic planning (Zungu, 2000). The problems as summarised under the three headings culminates in various stressors for both SETA employees and stakeholders.

If real results in the struggle against unemployment, illiteracy and the low skill level of the South African workforce are to be achieved through the implementation of the NSDS as a broad human resource development intervention, increased public demand for, and growing dissatisfaction with, skills delivery, increased private and public institution participation in skills development, and increased involvement from organised labour have increased the necessity for SETAs to 
achieve set objectives. SETAs need to function effectively and efficiently in the challenging environment of skills development.

The concepts of burnout and work engagement (which represent the concept of work-related well-being) are relevant when the effectiveness and efficiency of SETAs are considered. These two concepts provide indications of employees' energy at work (varying from exhaustion to vigour) and identification with work (varying from cynicism to dedication). Exhaustion and cynicism (as dimensions of work-related well-being of employees) are stress reactions, which might lead to less effective performance (Warr, 2002). Vigour and dedication represent positive work-related feelings, which might result in more effective performance. These dimensions of work-related well-being (i.e. exhaustion, cynicism, vigour and dedication) could be predicted by personal factors (e.g. sense of coherence) and situational factors (e.g. job demands and job resources). These factors can be combined in a model of work-related well-being.

\section{2}

\section{A model of work-related well-being}

\subsection{Burnout and work engagement}

According to Maslach et al. (2001), burnout can be defined as encompassing the components of emotional exhaustion, depersonalisation and reduced personal accomplishment. In the early days of burnout research, it was believed that burnout only existed in employees working in the human services. However, burnout, has since been expanded towards all types of professions and occupational groups, and this study aims to include SETA employees in the list. By means of the Maslach Burnout Inventory - General Survey (MBI-GS) ( Schaufeli, Leiter, Maslach \& Jackson, 1996), it is possible to study burnout in all types of professions and in all occupational groups.

Exhaustion refers to a state where all energy has been drained, whereas cynicism refers to an employee's unwillingness to perform because of an increased prejudice towards any effort. Cynicism can be viewed from the perspective that an employee is applying an adaptive mechanism to cope with excessive job demands and the resulting feelings of exhaustion (Maslach, Schaufeli \& Leiter, 2001). Schaufeli (2003) reports that when coping as a strategy becomes routine, it disrupts satisfactory task performance and becomes dysfunctional. This in turn leads to an increase in job demands and exhaustion, which completes the crippling circle. Incapability and unwillingness to perform are considered two 'voices' in the same choir (Schaufeli, 2003). Empirical findings showed the central role of exhaustion (inability to perform) and mental distancing (unwillingness to perform) as opposed to the third component, namely lack of professional efficacy in workrelated well-being.

Research shows that even when exposed to high job demands and long working hours, some individuals do not show symptoms of burnout (Schaufeli \& Bakker, 2001). Instead, they seem to find pleasure in dealing with these challenges. From a positive psychology perspective (Seligman \& Csikszentmihalyi, 2000), such individuals could be perceived as being engaged in their work. Nelson and Simmons (2003), report that meaningful work leads to eustress, which can promote engagement even in challenging conditions. The focus on engagement as the positive direct opposite of burnout promises to yield new perspectives on interventions to promote healthy perceptions, beliefs and physical well-being (Salovey, Rothman, Detweiler \& Steward, 2000) and to alleviate burnout (Maslach et al., 2001).

According to Kahn (1990: 694), engagement refers to 'the harnessing of organisation members' selves to their work roles [by which they] employ and express themselves physically, cognitively and emotionally during role performances'. Disengaged employees become disconnected from their jobs and hide their true identity, thoughts and feelings during role performances. Schaufeli and Bakker (2004) define work engagement as 'a positive, fulfilling work-related state of mind that is characterised by vigour, dedication and absorption' (2004: 295). Vigour is defined as a positive affective response to one's ongoing interactions with significant elements in one's job and work 
environment that comprises the interconnected feelings of physical strength and emotional energy. Dedication is characterised by feelings of enthusiasm, pride in one's job, and by feeling inspired and challenged by it.

Exhaustion (low energy) and cynicism (poor identification) are the main features of burnout that are assessed by the Maslach Burnout Inventory (MBI) (Schaufeli, 2003), while the positive aspects of vigour (high energy) and dedication (strong identification) are measured by means of the Utrecht Work Engagement Scale (Schaufeli, Salanova, González-Romá \& Bakker, 2002). Encouraging psychometric results have been reported with the use of the Utrecht Work Engagement Scale (Schaufeli, Martinez, Marques, Pinto, Salanova \& Bakker, 2002; Schaufeli, Salanova et al., 2002).

\subsection{Job demands and job resources}

Job demands and resources could affect the work-related well-being of individuals. The Comprehensive Burnout and Engagement model (Schaufeli \& Bakker, 2004) assumes two job-related psychological processes. The first process, an energetic process, links job demands with health problems via burnout. The second process, a motivational process, links job resources via work engagement with organisational commitment. Job resources may play either an extrinsic motivational role (by being instrumental in achieving work goals) or an intrinsic motivational role (by fostering the employee's growth, learning and development). The model was confirmed in a study by Schaufeli and Bakker (2004). Job demands were associated with exhaustion, whereas job resources were associated with work engagement.

Job demands are defined as the tasks that have to be performed by the occupant of a position (Demerouti, Bakker, Nachreiner \& Schaufeli, 2001). These tasks can include physical, social and organisational dimensions. Performing these tasks may require sustained physical and mental effort. Quantitative job demands refer to the amount of work required in relation to the time available, while qualitative workload involves employees' emotional reactions to their jobs (Cooper, Dewe \& O’Driscoll, 2001). High levels of job demands are associated with low work-related well-being, i.e. high exhaustion and cynicism (Schaufeli \& Bakker, 2004; Warr, 2002).

Job resources can be defined as those physical, psychological, social or organisational aspects of the job that may be purposeful in achieving work goals, reducing job demands and stimulating personal growth and development (Demerouti et al., 2001). Job resources, such as diversity, autonomy, opportunities for learning and growth, opportunities to participate, role clarity, effective and constructive communication, advancement, remuneration and good relationships with supervisors and colleagues, create psychological meaningfulness and safety for employees - which are needed for an employee to be engaged in his or her job (May, Gilson \& Harter, 2004). Warr (2002) confirms that job resources (e.g. autonomy) are related to high levels of enthusiasm of employees.

\subsection{Sense of coherence}

Individual characteristics of employees can affect their work-related well-being (i.e. exhaustion, cynicism, vigour and dedication). One such characteristic is sense of coherence (Antonovsky, 1987). Antonovsky defines sense of coherence as a relatively stable dispositional orientation. Antonovsky (1987) reports that each person's sense of coherence requires certain inherent fundamentals for coping successfully, which are in turn represented by the concepts of comprehensibility, manageability and meaningfulness. Comprehensibility refers to the extent to which people find or structure their world to be understandable, meaningful, orderly and consistent instead of disorderly, random and unpredictable. Individuals with high levels of coherence perceive their world as comprehensible and as making sense on a cognitive level. Manageability refers to the extent to which people experience events in life as situations that are endurable or manageable. Individuals with high levels of coherence feel that they have the resources to meet demands, or feel that they know where to obtain help. Meaningfulness refers to the extent to which one feels that life makes sense on an emotional level, and that life's challenges are worthy of commitment. 
A strong sense of coherence might assist employees to understand job demands and resources and to perceive them as manageable and meaningful. It can then be argued that a weak sense of coherence will lead employees to perceive situations as threatening (i.e. high job demands and low job resources), which in turn could lead to exhaustion and cynicism of employees. On the other hand, a strong sense of coherence will lead employees to perceive situations as challenges, which in turn will have a positive effect on vigour and dedication.

\section{3}

\section{Study objective}

The objective of this study was to investigate the relationship between job demands, job resources, sense of coherence and work-related well-being (i.e. burnout and work engagement) of employees at SETAs in South Africa.

\section{4 \\ Method}

\subsection{Research design}

A cross-sectional survey design was used in this study.

\subsection{Participants}

The study population consisted of employees from six different SETAs in South Africa. Convenient sampling was used for the purposes of this study. The total available population of staff members of various SETAs $(N=$ 286) was invited to participate in the study. Questionnaires were sent out to the total population of employees in MERSETA $(n=$ $92), \operatorname{FASSET}(n=16)$, FoodBev $(n=23)$, TETA $(n=41)$, HWSETA $(n=55)$, and CHIETA $(n$ $=52$ ). Descriptive information of the sample of SETA employees is given in Table 1.

Table 1

Characteristics of SETA employees in the sample

\begin{tabular}{|l|l|r|c|}
\hline Item & Category & Frequency & Percentage \\
\hline \multirow{2}{*}{ SETA } & MERSETA (Manufacturing, Engineering and Related Services) & 56 & 35.20 \\
& HWSETA (Health and Welfare) & 33 & 20.08 \\
& CHIETA (Chemical) & 19 & 11.90 \\
& FOODBEV (Food and Beverages) & 12 & 7.50 \\
& FASSET (Financial and Accounting) & 11 & 6.90 \\
& TETA (Transport) & 5 & 3.10 \\
& Others & 24 & 15.32 \\
\hline \multirow{2}{*}{ Education } & Grade 12 & 67 & 44.40 \\
& Three-year degree & 24 & 33.80 \\
& Four-year degree & 5 & 15.90 \\
& Five- to seven-year degree & 4 & 3.30 \\
& Master's degree & 55 & 2.60 \\
\hline \multirow{2}{*}{ Gender } & Male & 104 & 34.6 \\
& Female & 55.4 \\
\hline
\end{tabular}

The sample consisted mainly of female, Englishspeaking employees, working in SETAs. Forty-six per cent of the participants were married. Table 1 shows that more than a third of the participants were in possession of a three-year degree. Thirtyeight per cent of the participants were English speaking, 15.8 per cent were IsiZulu speaking, while 15.2 per cent spoke Afrikaans. The majority of the group (57.9 per cent) were in the employ of their SETA for less than two years, and 71.7 per cent of the participants had been in their current positions for less than a year. 


\subsection{Measuring battery}

An adapted version of the Maslach Burnout Inventory - General Survey (MBI-GS; Maslach et al., 1996) was used to measure burnout. The following subscales of the MBI-GS were used: exhaustion (e.g. 'I feel used up at the end of the workday') and cynicism (e.g. 'I have become less enthusiastic about my work'). All items were scored on a seven-point frequency rating scale ranging from 0 (never) to 6 (daily). Thirteen items loaded significantly on two scales: exhaustion (5 items) and cynicism (8 items). Jackson (2004) confirmed the construct equivalence and construct validity of these scales for educators in South Africa. The internal consistencies (Cronbach's alpha coefficients) reported by Schaufeli et al. (1996) varied from 0.87 to 0.89 for exhaustion and from 0.73 to 0.84 for cynicism. Test-retest reliabilities after one year were 0.65 (exhaustion) and 0.60 (cynicism). Storm and Rothmann (2003a) found support for the construct validity of the MBI-GS.

The Utrecht Work Engagement Scale (UWES) was developed by Schaufeli, Salanova et al. (2002) as a measure of engagement. For the purpose of this study, only two of the three subscales of the UWES were used, namely vigour ( 6 items; e.g. 'I am bursting with energy in my work') and dedication (5 items; e.g. 'I find my work full of meaning and purpose'). The items are scored on a frequency rating scale varying from 0 (never) to 6 (daily). The alpha coefficients for the subscales varied between 0.68 and 0.91 (Schaufeli et al., 2002). Studies making use of confirmative factor analysis demonstrated the factorial validity of the UWES (Schaufeli \& Bakker, 2004; Schaufeli, Salanova et al., 2002). In a South African study, Storm and Rothmann (2003b) obtained acceptable alpha coefficients for the two subscales ( 0.78 for vigour and 0.89 for dedication). Naudé (2003), in a study working with a sample of emergency workers in South Africa, found values of 0.70 for vigour and 0.83 for dedication. Jackson (2004) reported that the UWES shows construct equivalence and construct validity for educators in South Africa.

The Job Demands-Resources Scale (JDRS) was developed to measure job demands and job resources. The JDRS consists of 48 items, which are rated on a scale ranging from 1 (never) to 4 (always). Rothmann, Strydom and Mostert (2006) studied the construct validity, construct equivalence and reliability of the JDRS. They found that the JDRS measures five factors. Overload refers to pace and amount of work, mental load and emotional load. Growth Opportunities refers to having enough variety, opportunities to learn and independence in the job. Organisational Support measures the relationship with supervisors and colleagues, flow of information, communication, role clarity and participation in decision-making. Advancement refers to remuneration, career possibilities and training opportunities. Job Insecurity refers to uncertainty about the future. Rothmann et al. (2006) found the following reliabilities for the factors.: Overload $(\alpha=0.76)$, Growth Opportunities $(\alpha=0.86)$, Organisational Support ( $\alpha=0.92)$, Advancement $(\alpha=0.83)$, and Job Insecurity $(\alpha=0.89)$. All factors showed acceptable equivalence for different organisations.

The Orientation to Life Questionnaire (OLQ) (Antonovsky, 1987) was used to measure the participants' sense of coherence. The OLQ consists of 29 items. Antonovsky (1993) reported Cronbach alpha coefficients of the OLQ in 29 studies varying from 0.85 to 0.91 . Antonovsky also found test-retest reliability coefficients between 0.41 and 0.97. Rothmann (2002) reported an acceptable alpha coefficient of 0.89 for the OLQ (Nunnally \& Bernstein, 1994). In terms of the construct validity of the OLQ, a negative relationship was found to exist between OLQ and experienced stress. It was also found that the OLQ correlates negatively with the 'State-Trait Anxiety Inventory-Trait' and the 'Beck Depression Inventory' (Frenz, Carey \& Jorgensen, 1993).

\subsection{Statistical analysis}

Firstly, descriptive statistics (e.g. means, and standard deviations) were used to explore the data. Secondly, exploratory factor analyses were carried out. Eigenvalues and scree plots were studied to determine the number of factors involved. Principal axis factor analysis 
with a direct oblimin rotation was conducted if factors were related, and a varimax rotation was used if the obtained factors were not related (Tabachnick \& Fidell, 2001). Cronbach's alpha coefficients were then computed to assess the reliability of the constructs that were measured in this study.

To specify the relationship between the variables, Pearson product-moment correlation coefficients were computed. In terms of statistical significance, it was decided to set the value at a 95 per cent confidence interval level ( $p \leq 0.05$ ). Effect sizes (Steyn, 1999) were used to decide on the practical significance of the findings. A cut-off point of 0.30 (medium effect, Cohen, 1988) was set for the practical significance of correlation coefficients.

Structural equation modelling, as implemented by Amos (Arbuckle, 1999), was used to test the construct validity of the measuring instruments, using the maximum likelihood method. One of the fit indices produced by the Amos programme is the Chi-square statistic $\left(\chi^{2}\right)$, which is test of absolute fit of the model. However, the $\chi^{2}$ value is sensitive to sample size. Therefore additional goodness-of-fit indices, such as the Goodnessof-Fit Index (GFI), the Adjusted Goodness-ofFit Index (AGFI), the Normed Fit Index (NFI), the Comparative Fit Index (CFI), the TuckerLewis Index (TLI), and the Root Means Square Error of Approximation (RMSEA), were used in this study.

\section{5}

\section{Results}

\subsection{Construct validity of the measuring instruments}

Burnout and work engagement. Two models of burnout, namely a one-factor model and a twofactor model, were tested with SEM analysis. In the one-factor model, it was hypothesised that items measuring exhaustion and cynicism load on a single factor. The goodness-of-fit statistics for the one-factor model were as follows: $\chi^{2}=$ $102.87, p<0.01 ; \chi^{2} / d f=3.81 ; \mathrm{GFI}=0.85$; AGFI $=0.75 ; \mathrm{CFI}=0.79 ; \mathrm{NFI}=0.74 ; \mathrm{TLI}=0.72$ and RMSEA $=0.13$. In the two-factor model, it was hypothesised that exhaustion and cynicism are separate, but related, dimensions of burnout. The goodness-of-fit statistics for the two-factor model were as follows: $\chi^{2}=46.16, p<0.01$; $\chi^{2} / d f=1.78 ; \mathrm{GFI}=0.94 ; \mathrm{AGFI}=0.90 ; \mathrm{CFI}=$ $0.94 ; \mathrm{NFI}=0.88 ; \mathrm{TLI}=0.92 ; \mathrm{RMSEA}=0.07$. The above-mentioned statistics show that a twofactor model of burnout fitted the data better than a one-factor model.

Two models of work engagement were also tested, namely a one-factor model and a twofactor model. In the one-factor model, it was hypothesised that items measuring vigour and dedication load on a single factor. The following goodness-of-fit statistics were obtained for a one-factor model of work engagement: $\chi^{2}=$ 93.88, $p<0.01 ; \chi^{2} / d f=2.67$; GFI $=0.90$; AGFI $=0.85 ; \mathrm{CFI}=0.88 ; \mathrm{NFI}=0.82 ; \mathrm{TLI}=0.84$ and RMSEA $=0.10$. In the two-factor model, it was hypothesised that vigour and dedication are separate, but related, dimensions of work engagement. The goodness-of-fit statistics for the two-factor model are as follows: $\chi^{2}=$ 73.62, $p<0.01 ; \chi^{2} / d f=2.83$; GFI $=0.91$; AGFI $=0.85 ; \mathrm{CFI}=0.90 ; \mathrm{NFI}=0.85 ; \mathrm{TLI}=0.86$ and RMSEA $=0.10$. The above-mentioned statistics show that a two-factor model of work engagement fitted the data better than a onefactor model.

\subsection{Descriptive statistics, reliabilities and correlations}

The descriptive statistics, reliability, and correlations for the factors of the measuring instruments for SETA employees are given in Table 2. 


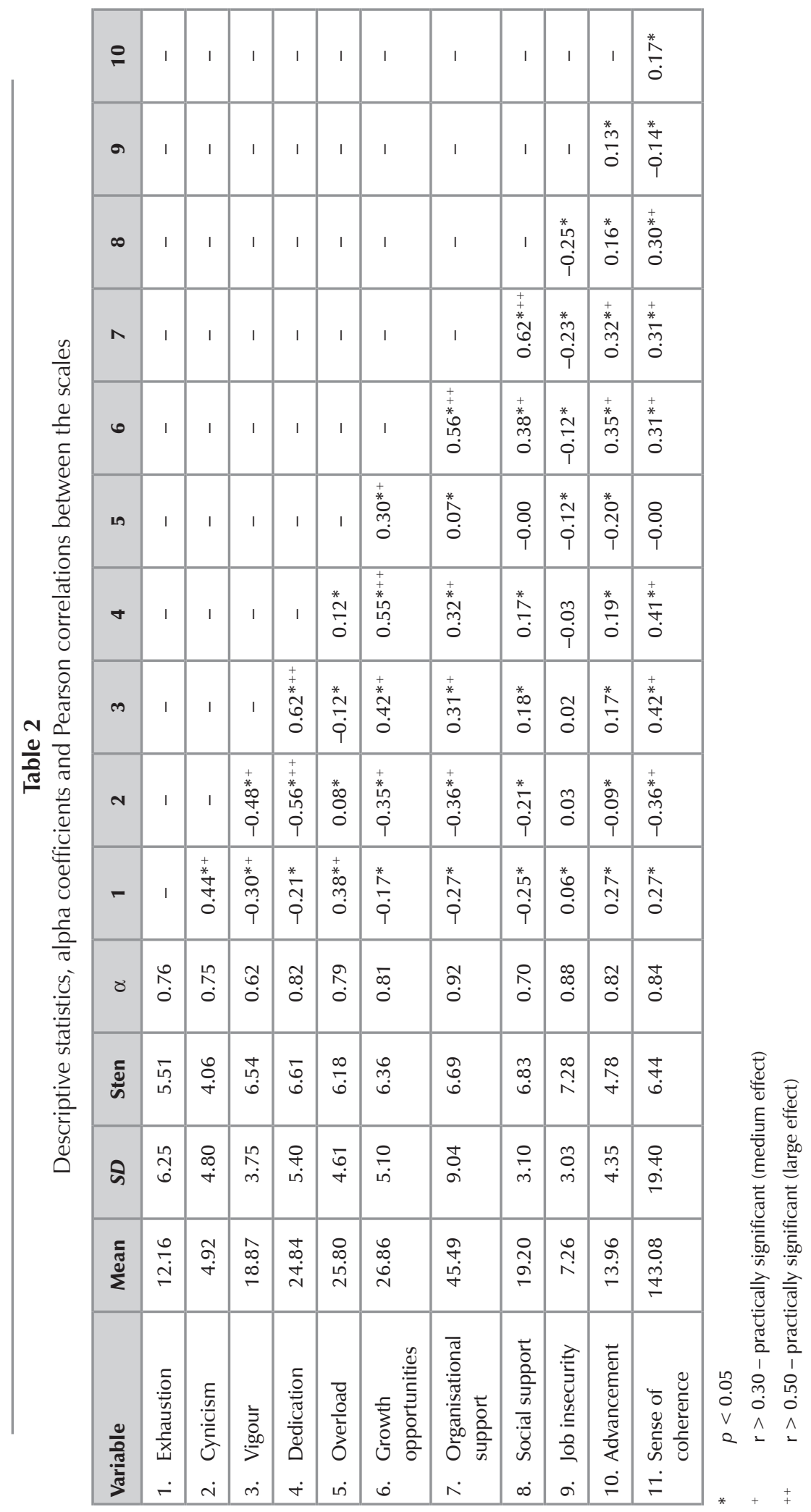


Analysis of Table 2 revealed that acceptable alpha coefficients, ranging from 0.70 to 0.92 , were obtained for the scales - with the exception of vigour $(\alpha=0.62)$. The alpha coefficients of the scales compare favourably with the guideline of $\alpha>0.70$ (Nunnally \& Bernstein, 1994).

Table 2 shows the stens of the different variables relatively to South African norms. It is evident from Table 2 that participants perceived Advancement to be below average compared to the norm. Job insecurity seems to be above average compared to the South African norm. Not shown in Table 2, are the percentages of employees who experience low, moderate or high levels of exhaustion, cynicism, vigour and dedication. It is evident that the level of exhaustion is average compared to the norm. The level of cynicism is below average, while the levels of vigour and dedication are somewhat higher than the average (Rothmann, 2005).

Table 2 shows a statistically and practically significant correlation (of medium effect) between exhaustion and cynicism. Exhaustion is statistically and practically significantly related to overload (medium effect). Cynicism is statistically and practically significantly negatively related to dedication (large effect), growth opportunities, organisational support, and sense of coherence (all medium effects). Exhaustion and cynicism are statistically and practically significantly negatively related to vigour (medium effects). Vigour is statistically and practically significantly related to dedication and dedication to growth opportunities (large effect). Vigour and dedication are statistically and practically significantly related to organisational support, and sense of coherence (all medium effects).

\subsection{Multiple regression analyses}

The results of a multiple regression analysis with exhaustion as dependent variable are reported in Table 3.

Table 3

Multiple regression analysis with exhaustion as dependent variable

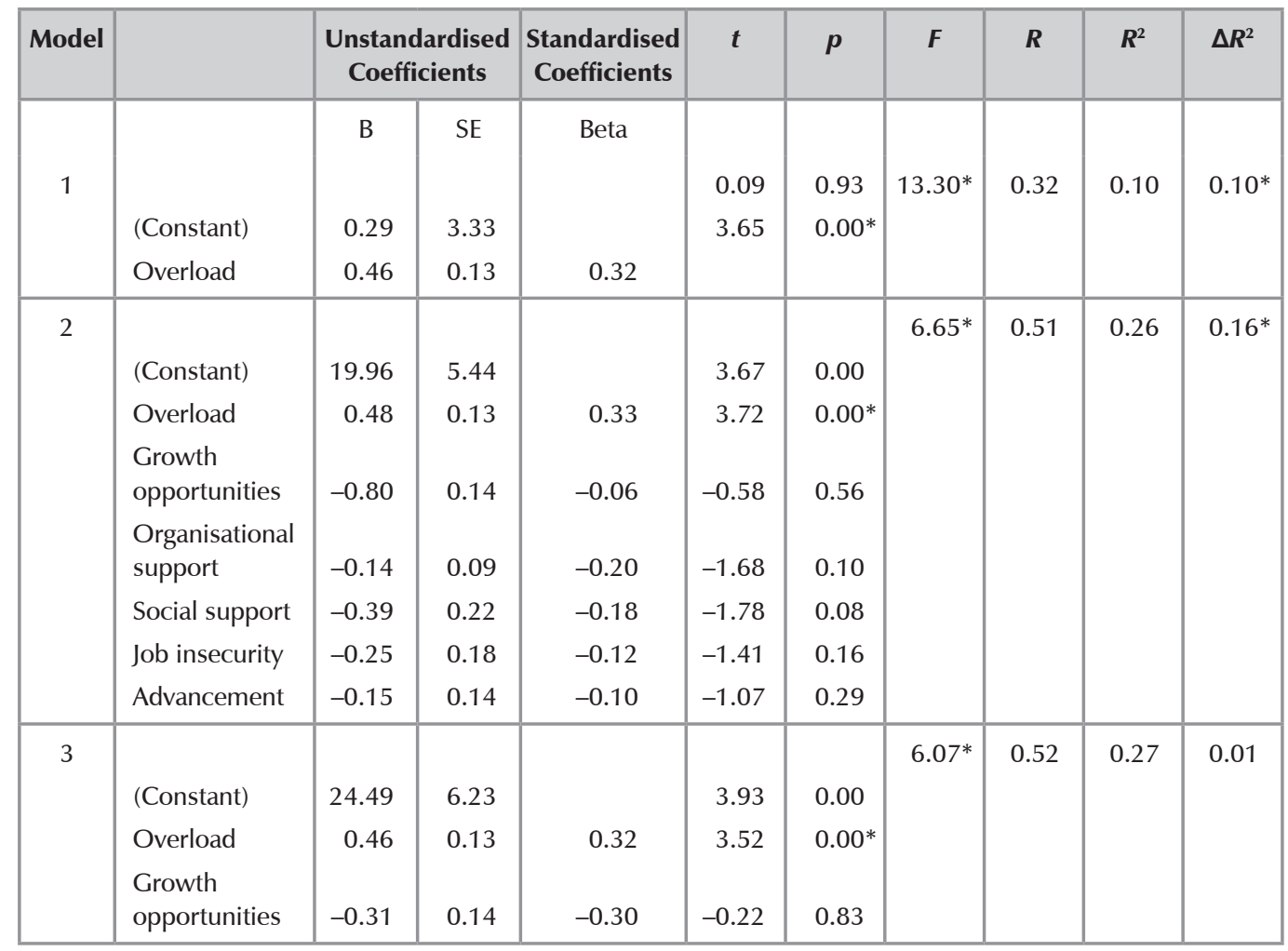




\begin{tabular}{|l|l|l|l|l|l|l|l|l|l|}
\hline & & & & & & & & \\
Organisational & & & & & & & \\
& support & -0.14 & 0.09 & -0.19 & -1.63 & 0.11 & & \\
Social support & -0.35 & 0.22 & -0.16 & -1.59 & 0.12 & & \\
Job insecurity & -0.28 & 0.18 & -0.13 & -1.56 & 0.12 & & \\
Advancement & -0.15 & 0.14 & -0.10 & -1.08 & 0.28 & & \\
Sense of & & & & & & & \\
coherence & -0.04 & 0.03 & -0.13 & -1.47 & 0.14 & & & \\
\hline
\end{tabular}

* $p<0.05$

Table 3 shows that overload explained 10 per cent of the variance in exhaustion. The lack of job resources, i.e. growth opportunities, organisational support, social support, job insecurity and advancement in the presence of overload, explained another 16 per cent of the variance in exhaustion, with a lack of organisational support the most significant of these job resources. However, none of the regression coefficients of job resources were statistically significant at $p<0.05$. Table 3 shows that the lack of job resources in the presence of overload explained 26 per cent of the variance in exhaustion. In addition, Table 3 shows that a sense of coherence did not add statistically significantly to the explanation of exhaustion.

The results of the multiple regression analysis with cynicism as dependent variable are shown in Table 4.

Table 4

Multiple regression analysis with cynicism as dependent variable

\begin{tabular}{|c|c|c|c|c|c|c|c|c|c|c|}
\hline \multirow{3}{*}{$\begin{array}{c}\text { Model } \\
1 \\
1\end{array}$} & & \multicolumn{2}{|c|}{$\begin{array}{l}\text { Unstandardised } \\
\text { Coefficients }\end{array}$} & \multirow{2}{*}{$\begin{array}{c}\text { Standardised } \\
\text { Coefficients }\end{array}$} & \multirow[t]{2}{*}{$t$} & \multirow[t]{2}{*}{$p$} & \multirow[t]{2}{*}{$\boldsymbol{F}$} & \multirow[t]{2}{*}{$\boldsymbol{R}$} & \multirow[t]{2}{*}{$R^{2}$} & \multirow[t]{2}{*}{$\Delta R^{2}$} \\
\hline & & B & SE & & & & & & & \\
\hline & & & & & & & $5.70^{*}$ & 0.45 & 0.20 & $0.20^{*}$ \\
\hline & (Constant) & 17.33 & 3.51 & & 4.94 & 0.00 & & & & \\
\hline & $\begin{array}{l}\text { Growth } \\
\text { opportunities }\end{array}$ & -0.29 & 0.10 & -0.31 & -2.86 & $0.01 *$ & & & & \\
\hline & $\begin{array}{l}\text { Organisational } \\
\text { support }\end{array}$ & -0.14 & 0.07 & -0.25 & -2.11 & $0.04 *$ & & & & \\
\hline & Social support & 0.01 & 0.17 & 0.01 & 0.05 & 0.96 & & & & \\
\hline & Job insecurity & -0.17 & 0.14 & -0.11 & -1.24 & 0.22 & & & & \\
\hline & Advancement & 0.18 & 0.10 & 0.17 & 1.81 & 0.07 & & & & \\
\hline 2 & & & & & & & $5.21^{*}$ & 0.46 & 0.22 & 0.01 \\
\hline & (Constant) & 13.72 & 4.19 & & 3.27 & 0.00 & & & & \\
\hline & $\begin{array}{l}\text { Growth } \\
\text { opportunities }\end{array}$ & -0.34 & 0.11 & -0.36 & -3.24 & $0.00 *$ & & & & \\
\hline & $\begin{array}{l}\text { Organisational } \\
\text { support }\end{array}$ & -0.14 & 0.07 & -0.25 & -2.10 & $0.04^{*}$ & & & & \\
\hline & Social support & 0.20 & 0.17 & 0.01 & 0.10 & 0.93 & & & & \\
\hline & Job insecurity & -0.16 & 0.14 & -0.10 & -1.13 & 0.26 & & & & \\
\hline & Advancement & 0.23 & 0.10 & 0.21 & 2.21 & $0.03 *$ & & & & \\
\hline & Overload & 0.16 & 0.10 & 0.14 & 1.56 & 0.12 & & & & \\
\hline
\end{tabular}




\begin{tabular}{|c|c|c|c|c|c|c|c|c|c|c|}
\hline 3 & $\begin{array}{l}\text { (Constant) } \\
\text { Growth } \\
\text { opportunities } \\
\text { Organisational } \\
\text { support } \\
\text { Social support } \\
\text { Job insecurity } \\
\text { Advancement } \\
\text { Overload } \\
\text { Sense of } \\
\text { coherence }\end{array}$ & $\begin{array}{r}21.26 \\
-0.26 \\
-0.13 \\
0.09 \\
-0.20 \\
0.23 \\
0.12 \\
-0.07\end{array}$ & $\begin{array}{l}4.63 \\
0.10 \\
0.06 \\
0.17 \\
0.13 \\
0.10 \\
0.10 \\
\\
0.21\end{array}$ & $\begin{array}{r}-0.28 \\
-0.23 \\
0.05 \\
-0.13 \\
0.21 \\
0.11 \\
-0.29\end{array}$ & $\begin{array}{r}4.60 \\
-2.50 \\
-2.05 \\
0.52 \\
-1.50 \\
2.29 \\
1.19 \\
-3.30\end{array}$ & $\begin{array}{l}0.00 \\
0.01 * \\
0.04 * \\
0.61 \\
0.14 \\
0.02 * \\
0.24 \\
0.00 *\end{array}$ & $6.40^{*}$ & 0.53 & 0.28 & $0.06^{*}$ \\
\hline
\end{tabular}

* $\quad p<0.05$

It is clear from Table 4 that a lack of job resources explained 20 per cent of the variance in cynicism. Only two categories of job resources added statistically significantly to the percentage of variance explained, namely growth opportunities and organisational support. No statistically significant increase in $R^{2}$ realised when overload was added to the prediction. However, when sense of coherence was entered in the third step, $R^{2}$ increased statistically significantly $\left(\Delta R^{2}\right.$ $=6$ per cent). Therefore, a lack of growth opportunities, a lack of organisational support, and a weak sense of coherence contributed to cynicism in this study.

The results of a multiple regression analysis with vigour as dependent variable and job demands, job resources and sense of coherence as independent variables are reported in Table 5 .

Table 5

Multiple regression analysis with vigour as dependent variable

\begin{tabular}{|c|c|c|c|c|c|c|c|c|c|c|}
\hline \multirow{3}{*}{$\begin{array}{c}\text { Model } \\
1 \\
\end{array}$} & & \multicolumn{2}{|c|}{$\begin{array}{l}\text { Unstandardised } \\
\text { Coefficients }\end{array}$} & \multirow{2}{*}{$\begin{array}{c}\begin{array}{c}\text { Standardised } \\
\text { Coefficients }\end{array} \\
\text { Beta }\end{array}$} & \multirow[t]{2}{*}{$t$} & \multirow[t]{2}{*}{$p$} & \multirow[t]{2}{*}{$\boldsymbol{F}$} & \multirow[t]{2}{*}{$\boldsymbol{R}$} & \multirow[t]{2}{*}{$R^{2}$} & \multirow[t]{2}{*}{$\Delta R^{2}$} \\
\hline & & B & SE & & & & & & & \\
\hline & & & & & & & $7.38^{*}$ & 0.49 & 0.24 & $0.24^{*}$ \\
\hline & (Constant) & 7.42 & 2.79 & & 2.66 & 0.01 & & & & \\
\hline & $\begin{array}{l}\text { Growth } \\
\text { opportunities }\end{array}$ & 0.32 & 0.08 & 0.42 & 4.03 & $0.00^{*}$ & & & & \\
\hline & Organisational & & & & & & & & & \\
\hline & & 0.08 & 0.05 & 0.17 & $1.4 /$ & 0.14 & & & & \\
\hline & Social support & -0.07 & 0.14 & -0.05 & -0.51 & 0.61 & & & & \\
\hline & Job insecurity & 0.13 & 0.11 & 0.10 & 1.15 & 0.25 & & & & \\
\hline & Advancement & -0.04 & 0.08 & -0.05 & -0.56 & 0.58 & & & & \\
\hline 2 & & & & & & & $6.91 *$ & 0.52 & 0.27 & 0.03 \\
\hline & (Constant) & 1.095 & 3.31 & & 3.30 & 0.00 & & & & \\
\hline & Growth & 0.37 & 0.08 & 0.49 & 4.48 & $0.00^{*}$ & & & & \\
\hline & $\begin{array}{l}\text { Organisational } \\
\text { support }\end{array}$ & 0.08 & 0.05 & 0.17 & 1.45 & 0.15 & & & & \\
\hline & Social support & -0.08 & 0.14 & -0.06 & -0.57 & 0.57 & & & & \\
\hline & Job insecurity & 0.11 & 0.11 & 0.09 & 1.03 & 0.31 & & & & \\
\hline & Advancement & -0.09 & 0.08 & -0.11 & -1.13 & 0.26 & & & & \\
\hline & Overload & -0.15 & 0.08 & -0.17 & -1.92 & 0.06 & & & & \\
\hline
\end{tabular}




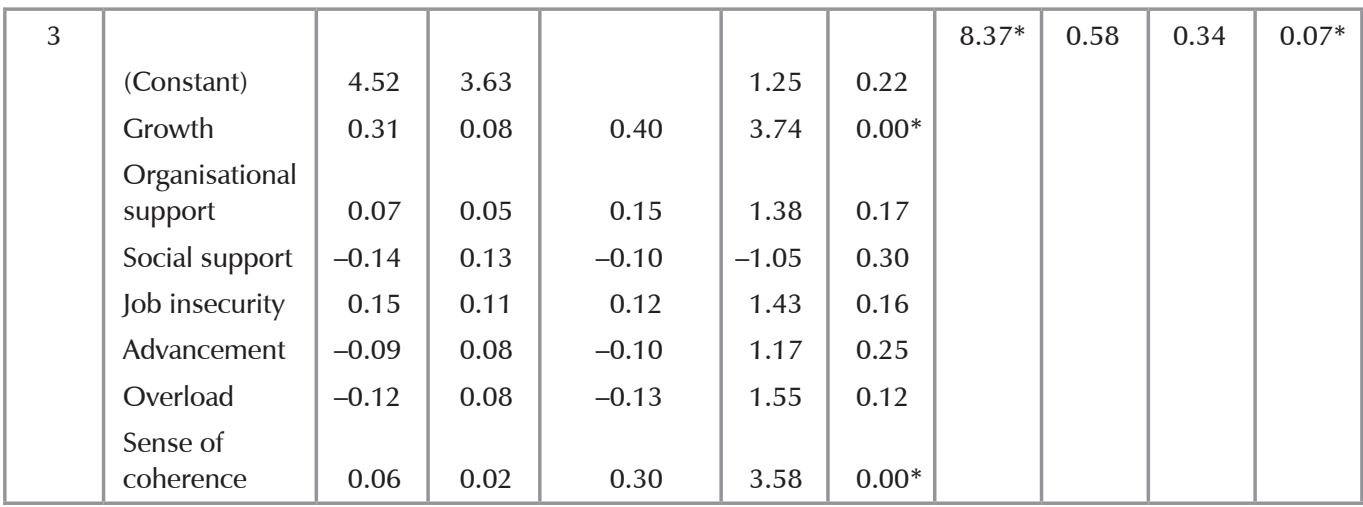

* $p<0.05$

Table 5 shows that job resources predicted 24 per cent of the variance in vigour. However, only the regression coefficient of growth opportunities was statistically significant. No statistically significant increase was reported in the total variance explained when overload was added to the model. When sense of coherence was added to the model, a statistically significant increase in $R^{2}$ was again observed $\left(\Delta R^{2}=7\right.$ per cent). Therefore, vigour is best predicted by growth opportunities in the job (variety, learning opportunities and autonomy), and a strong sense of coherence.

The results of a multiple regression analysis with dedication as dependent variable and job demands, job resources and sense of coherence as independent variables are reported in Table 6.

Table 6

Multiple regression analysis with dedication as dependent variable

\begin{tabular}{|c|c|c|c|c|c|c|c|c|c|c|}
\hline \multirow{3}{*}{$\begin{array}{c}\text { Model } \\
1 \\
1\end{array}$} & & \multicolumn{2}{|c|}{$\begin{array}{c}\text { Unstandardised } \\
\text { Coefficients }\end{array}$} & \multirow{2}{*}{$\begin{array}{c}\text { Standardised } \\
\text { Coefficients }\end{array}$} & \multirow[t]{2}{*}{$t$} & \multirow[t]{2}{*}{$p$} & \multirow[t]{2}{*}{$F$} & \multirow[t]{2}{*}{$\boldsymbol{R}$} & \multirow[t]{2}{*}{$R^{2}$} & \multirow[t]{2}{*}{$\Delta R^{2}$} \\
\hline & \multirow{9}{*}{$\begin{array}{l}\text { (Constant) } \\
\text { Growth } \\
\text { opportunities } \\
\text { Organisational } \\
\text { support } \\
\text { Social support } \\
\text { Job insecurity } \\
\text { Advancement }\end{array}$} & B & SE & & & & & & & \\
\hline & & & & & & & \multirow[t]{8}{*}{$13.89 *$} & \multirow[t]{8}{*}{0.61} & \multirow[t]{8}{*}{0.38} & \multirow{8}{*}{$0.38^{*}$} \\
\hline & & 8.40 & 3.63 & & 2.32 & 0.02 & & & & \\
\hline & & 0.67 & 0.10 & 0.61 & 6.51 & $0.00 *$ & & & & \\
\hline & & & & & & & & & & \\
\hline & & 0.04 & 0.07 & 0.06 & 0.57 & 0.57 & & & & \\
\hline & & -0.20 & 0.18 & -0.10 & -1.13 & 0.26 & & & & \\
\hline & & 0.06 & 0.14 & 0.03 & 0.42 & 0.68 & & & & \\
\hline & & -0.01 & 0.10 & -0.01 & -0.13 & 0.89 & & & & \\
\hline \multirow[t]{8}{*}{2} & & & & & & & \multirow[t]{8}{*}{$11.48^{*}$} & \multirow[t]{8}{*}{0.61} & \multirow[t]{8}{*}{0.38} & \multirow[t]{8}{*}{0.00} \\
\hline & (Constant) & 8.07 & 4.37 & & 1.84 & 0.07 & & & & \\
\hline & $\begin{array}{l}\text { Growth } \\
\text { opportunities }\end{array}$ & 0.67 & 0.11 & 0.61 & 6.06 & $0.00 *$ & & & & \\
\hline & $\begin{array}{l}\text { Organisational } \\
\text { support }\end{array}$ & 0.04 & 0.07 & 0.06 & 0.57 & 0.57 & & & & \\
\hline & Social support & -0.20 & 0.18 & -0.10 & -1.12 & 0.27 & & & & \\
\hline & Job insecurity & 0.06 & 0.15 & 0.03 & 0.42 & 0.67 & & & & \\
\hline & Advancement & -0.01 & 0.11 & -0.01 & -0.09 & 0.93 & & & & \\
\hline & Overload & 0.01 & 0.11 & 0.01 & 0.14 & 0.89 & & & & \\
\hline
\end{tabular}




\begin{tabular}{|c|c|c|c|c|c|c|c|c|c|c|}
\hline 3 & $\begin{array}{l}\text { (Constant) } \\
\text { Growth } \\
\text { opportunities } \\
\text { Organisational } \\
\text { support } \\
\text { Social support } \\
\text { Job insecurity } \\
\text { Advancement } \\
\text { Overload } \\
\text { Sense of } \\
\text { coherence }\end{array}$ & $\begin{array}{r}-0.04 \\
0.58 \\
0.03 \\
-0.27 \\
0.11 \\
-0.01 \\
0.06 \\
0.08\end{array}$ & $\begin{array}{l}4.81 \\
0.11 \\
0.07 \\
0.17 \\
0.14 \\
0.10 \\
0.10 \\
0.02\end{array}$ & $\begin{array}{r}0.53 \\
0.05 \\
-0.14 \\
0.06 \\
-0.01 \\
0.05 \\
0.30\end{array}$ & $\begin{array}{r}-0.01 \\
5.36 \\
0.46 \\
-1.59 \\
0.78 \\
-0.07 \\
0.57 \\
\\
3.40\end{array}$ & $\begin{array}{l}0.99 \\
0.00^{*} \\
0.65 \\
0.11 \\
0.44 \\
0.94 \\
0.57 \\
0.00^{*}\end{array}$ & $12.41^{*}$ & 0.66 & 0.44 & $0.06^{*}$ \\
\hline
\end{tabular}

* $\quad p<0.05$

Table 6 shows that job resources predicted 38 per cent of the variance in dedication. However, only the regression coefficient of growth opportunities was statistically significant. No statistically significant increase was reported in the total variance explained when overload was added to the model. When sense of coherence was added to the model, a statistically significant increase in $R^{2}$ was again observed $\left(\Delta R^{2}=6\right.$ per cent). Therefore, dedication is best predicted by growth opportunities in the job (variety, learning opportunities and autonomy), and a strong sense of coherence.

\section{6}

\section{Discussion}

The objective of this study was to investigate the relationship between job demands, job resources, sense of coherence and work-related well-being in 159 SETA employees, using a cross-sectional survey design.

The results of this study confirmed the two-factor structure of burnout, as well as work engagement. Burnout consisted of two factors, namely incapability (exhaustion) and unwillingness to perform (cynicism). Work engagement also consisted of two factors, namely capability (vigour) and willingness to perform (dedication). These factors probably represent the energy and identification dimensions of work-related well-being (Schaufeli \& Bakker, 2004). Low levels of burnout were related to high levels of engagement. Therefore, the findings of Schaufeli, Martinez, Pinto, et al. (2002) that burnout and engagement are related but distinct concepts, were confirmed in this study. It is clear from the results that exhaustion of SETA employees (indicating an incapability to perform) is average compared to the norm. However, the level of cynicism is below average compared to the norm. The results showed that job insecurity and a lack of advancement were problem areas in SETAs.

The results confirmed that overload (i.e. pace and amount of work, mental load and emotional load) was the best predictor of exhaustion of SETA employees, while it was not related to their cynicism, vigour, and/or dedication. Employees who face high overload may find it difficult to find sufficient energy to do their jobs properly. Overload might be a result of high demands or a lack of competence to perform a job.

Cynicism was exclusively predicted by a lack of job resources in this study. First, a lack of growth opportunities in the job (variety, opportunities to learn and independence in the job), and a lack of organisational support (the relationship with supervisors and colleagues, flow of information, communication, role clarity and participation in decision-making) predicted cynicism. Second, it was evident that poor advancement (remuneration, career possibilities and training opportunities) contributed to cynicism when overload was entered into the regression equation. Third, the results showed that a strong sense of coherence contributed to lower cynicism. Work engagement (including vigour and dedication) was exclusively predicted 
by growth opportunities in the job and a strong sense of coherence. Therefore, employees who perceived that they had variety, opportunities to learn and independence in their jobs, and who experienced stimuli as comprehensible, manageable and meaningful, showed higher levels of vigour and dedication at work.

In support of the results of Schaufeli and Bakker (2004), the results of this study showed that high job demands (overload), a lack of job resources (growth opportunities and organisational support), and a weak sense of coherence predicted high levels of burnout (exhaustion and cynicism). Burnout (consisting of exhaustion and cynicism) was negatively related to work engagement (consisting of vigour and dedication). On the positive side of wellness, high levels of job resources (specifically growth opportunities) predicted high levels of work engagement (vigour and dedication).

It seems that a weak sense of coherence contributed to work-related (un)well-being in various ways in this study. First, a weak sense of coherence predicted high levels of cynicism. Second, a strong sense of coherence predicted high levels of work engagement. This finding supports the findings of previous studies on sense of coherence (e.g. Basson \& Rothmann, 2002; Levert et al., 2000; Rothmann, 2004; Wissing, De Waal \& De Beer, 1992) which reported significant negative correlations between burnout and sense of coherence. It is possible that sense of coherence contributes to psychological meaningfulness, which may assist employees to ward off burnout and strengthen engagement inclinations (May et al., 2004). In line with the findings of Amirkhan and Greaves (2003), a strong sense of coherence impacted on perception, such that individuals with a strong orientation were likely to view a larger number of life events as having coherence.

In conclusion, the results of this study showed that the work-related well-being (exhaustion, cynicism, vigour and dedication) of SETA employees can be predicted by their perceptions of their job demands and job resources as well as their sense of coherence. It could be expected that high levels of exhaustion and cynicism and low levels of vigour and dedication will impact on the performance of employees.
The present study has certain limitations. A cross-sectional survey design was used. As a result, no causal inferences can be drawn. In future studies, longitudinal or experimental designs should be used to investigate causal relationships between the variables. Another limitation of this study was that measurement was based solely on self-reports. Therefore, at least part of the common variance of the measures could be attributed to method variance. In future studies, other measures of wellness (e.g. supervisor ratings and objective data) should be used in addition to selfreports. Third, methodological aspects such as the sample size as well as the non-probability sampling method could challenge the external validity of the current findings.

\section{7}

\section{Recommendations}

In order to improve levels of work-related wellbeing of employees as well as organisational efficiency and effectiveness, SETAs should design and implement organisational development interventions at systems level to deal with exhaustion and cynicism, and low vigour and dedication. Overload, a lack of growth opportunities, a lack of organisational support, poor advancement opportunities, and job insecurity should be addressed, because these factors had a significant impact on the work-related well-being (i.e. energy and identification with work) of SETA employees. Interventions can include the redesign of organisational structures, work flow, job descriptions, the development of performance models and performance agreements. Attending to these factors will probably contribute to the efficiency and effectiveness of SETAs.

Although it is important to assist individual SETA employees whose psychological wellbeing is affected by their work (by means of interventions such as counselling), primary and secondary interventions should be implemented in addition to tertiary interventions. The intention must be to address the levels of job demands and job resources within SETAs. Since job demands and a lack of job resources 
play a central role in burnout, it is necessary to implement preventative SETA-based solutions to tackle the problem of high levels of job demands and the lack of job resources available to individuals in the employ of SETAs.

The sense of coherence of SETA employees should also be taken into account during selection and management of employees. SETAs can contribute to the development of employees' sense of coherence by increasing the comprehensibility of stimuli (e.g. by providing information in an understandable format), manageability (e.g. by ensuring that employees are equipped with the necessary knowledge, skills, material, instruments and other resources), and meaningfulness (e.g. by allowing a degree of independence and freedom of choice in the performance of their tasks).

Future studies should test the relationships between job demands, job resources, sense of coherence, burnout, work engagement, illhealth, organisational commitment, and job performance in longitudinal research designs.

\section{Acknowledgement}

This material is based upon work supported by the National Research Foundation under grant number 2053917.

\section{References}

1 AMIRKHAN, J.H. \& GREAVES, H. (2003) "Sense of coherence and stress: The mechanics of a healthy disposition", Psychology and Health, 18(1): 31-62.

2 ANTONOVSKY, A. (1987) "Unraveling the Mystery of Health: How people Manage Stress and Stay Well. Jossey-Bass: San Francisco, CA.

3 ANTONOVSKY, A. (1993) "The structure and properties of the sense of coherence scale", Social Science and Medicine, 36: 725-733.

4 ARBUCKLE, J.L. (1999) Amos 4.0. Smallwaters: Chicago, IL.

5 BASSON. M.J. \& ROTHMANN, S. (2002) "Sense of coherence, coping and burnout of pharmacists", South African Journal of Economic and Management Sciences, 5(1): 35-62.

6 COHEN, J. (1988) Statistical Power Analysis for the Behavioral Sciences (revised ed.) Academic Press: Orlando, FL.
7 COOPER, C.L.; DEWE, P.J. \& O'DRISCOLL, M.P. (2001) Organizational Stress: A Review of Critique of Theory, Research, and Applications. Sage: Thousand Oaks, CA.

8 DEMEROUTI, E.; BAKKER, A.B.; NACHREINER, F. \& SCHAUFELI, W.B. (2001) "The job demands-resources model of burnout", Journal of Applied Psychology, 86: 499-512.

9 FRENZ, A.W.; CAREY, M.P. \& JORGENSEN, R.S. (1993) "Psychometric evaluation of Antonovsky's sense of coherence scale", Psychological Assessment, 5: 145-153.

10 JACKSON, L.T.B. (2004) "Burnout and work engagement of teachers in the North West Province", Unpublished doctoral thesis, NorthWest University, Potchefstroom, South Africa.

11 KAHN, W.A. (1990) "Psychological conditions of personal engagement and disengagement at work", Academy of Management Journal, 33: 692-724.

12 LEVERT, T., LUCAS, M. \& ORTLEPP, K. (2000) "Burnout in psychiatric nurses: Contributions of the work environment and a sense of coherence", South African Journal of Psychology, 30: 36-43.

13 MASLACH, C., JACKSON, S.E. \& LEITER, M. (1996) Maslach Burnout Inventory: Manual (3rd ed.) Consulting Psychologists Press: Palo Alto, CA.

14 MASLACH, C., SCHAUFELI, W.B. \& LEITER, M.P. (2001) "Job burnout", Annual Review of Psychology, 52: 397-422.

15 MAY, D.R.; GILSON, R.L. \& HARTER, L.M. (2004) "The psychological conditions and meaningfulness, safety and availability and the engagement of the human spirit at work", Journal of Occupational and Organizational Psychology, 77: $11-37$.

16 NAUDÉ, J.L.P. (2003) “Occupational stress, coping, burnout and work engagement of emergency workers in Gauteng", Unpublished doctoral thesis, PU for CHE, Potchefstroom.

17 NELSON, D.L. \& SIMMONS, B.L. (2003) "Health psychology and work stress: A more positive approach", In J.C. Quick \& L.E. Tetrick (eds.) Handbook of Occupational Health Psychology (pp. 97-119). American Psychological Association: Washington, DC.

18 NUNNALLY, J.C. \& BERNSTEIN, I.H. (1994) Psychometric Theory (3 ${ }^{\text {rd }}$ ed.) McGraw-Hill: New York.

19 ROTHMANN, S. (2002) "Burnout research in South Africa." Paper presented at the $1^{\text {st }}$ South African Conference on burnout, March, Potchefstroom.

20 ROTHMANN, S. (2004) "Burnout, psychological strengths and coping strategies of senior managers 
in the manufacturing industry", Management

Dynamics, 13(4): 26-37.

21 ROTHMANN, S. (2005) "Work-related wellbeing in South African organisations: What do we know?" Paper presented at the 7th Annual Conference of the Employee Assistance Professionals Association of South Africa, September, Durban.

22 ROTHMANN, S.; STRYDOM, M. \& MOSTERT, K. (2006) "A psychometric evaluation of the job demands-resources scale in South Africa”, South African Journal of Industrial Psychology, 32(4): 76-86.

23 SALOVEY, P.; ROTHMAN, A.J.; DETWEILER, J.B. \& STEWART, W.T. (2000) "Emotional states and physical health", American Psychologist, 55: 110-121.

24 SCHAUFELI, W.B. (2003) "Past performance and future perspectives of burnout research", South African Journal of Industrial Psychology, 29(4): 1-15.

25 SCHAUFELI, W.B. \& BAKKER, A.B. (2001) "Werk en welbevinden: Naar een positieve benadering in de Arbeids- en Gezondheidspsychologie" [Work and well-being: Towards a positive approach in occupational and health psychology]. Gedrag en Organisatie, 14: 229-253.

26 SCHAUFELI, W.B. \& BAKKER, A.B. (2004) “Job demands, job resources, and their relationship with burnout and engagement: A multi-sample study", Journal of Organizational Behavior, 25: 1-23.

27 SCHAUFELI, W.B.; LEITER, M.P.; MASLACH, C. \& JACKSON, S.E. (1996) "Maslach burnout inventory - general survey”, In C. Maslach, S.E. Jackson \& M.P. Leiter (eds.) Maslach Burnout Inventory Manual ( $3^{\text {rd }}$ ed.) Consulting Psychologists Press: Palo Alto, CA.

28 SCHAUFELI, W.B.; MARTINEZ, I.; PINTO, A.M.; SALANOVA, M. \& BAKKER A.B. (2002)
"Burnout and engagement in university students: A cross-national study", Journal of Cross-Cultural Psychology, 33: 464-481.

29 SCHAUFELI, W.B.; SALANOVA, M.; GONZÁLEZ-ROMÁ, V. \& BAKKER, A.B. (2002) "The measurement of engagement and burnout: A confirmatory analytic approach", Journal of Happiness Studies, 3: 71-92.

30 SELIGMAN, M.E.P. \& CSIKSZENTMIHALYI, M. (2000) "Positive psychology: An introduction", American Psychologist, 55: 5-14.

31 STEYN, H.S. (1999) "Praktiese beduidendheid: Die gebruik van effekgroottes", [Practical significance: The use of effect sizes.] Wetenskaplike bydraes - Reeks B: Natuurwetenskappe Nr 117. Potchefstroom: PU vir CHO.

32 STORM, K. \& ROTHMANN, S. (2003a) "A psychometric analysis of the Maslach Burnout Inventory - General survey in the South African Police Service", South African Journal of Psychology, 33: 219-226.

33 STORM, K. \& ROTHMANN, S. (2003b) "A psychometric analysis of the Utrecht Work engagement Scale in the South African Police Service", South African Journal of Industrial Psychology, 29(4): 62-70.

34 TABACHNICK B.G. \& FIDELL, L.S. (2001) Using Multivariate Statistics (4 ${ }^{\text {th }}$ ed.) Allyn \& Bacon: Boston MA.

35 WARR, P. (2002) "The study of well-being, behaviour and attitudes", In P. Warr (ed.) Psychology at Work (pp. 1-25) Penguin Books: London.

36 WISSING, M.P.; DE WAAL. M. \& DE BEER, I. (1992) "Sense of coherence and stress symptomatology", Paper presented at $25^{\text {th }}$ International Congress of Psychology, Brussels, Belgium.

37 ZUNGU, Z. (2000) "Setas must clean up their disgraceful show”, City Press, 10August: 2. 